\title{
Yüksek Kamu Binalarında Duman Tahliyesinin Simülasyon Metoduyla İncelenmesi
}

\author{
Investigation of Smoke Evacuation with Simulation Method in High Public Buildings
}

\author{
Mustafa Osman ISIKAN ${ }^{1}$ (D) Osman KAYA ${ }^{2}$ (D) \\ ${ }^{1}$ Marmara Üniversitesi, Teknoloji Fakültesi, Makine Mühendisliği, Termodinamik Ana Bilim Dal,,Marmara Üniversitesi \\ Göztepe Yerleşkesi 34722 Kadıköy/ISTANBUL. \\ ${ }^{2}$ Marmara Üniversitesi, Teknoloji Fakültesi, Makine Mühendisliği Ana Bilim Dal, Marmara Üniversitesi Göztepe \\ Yerleşkesi 34722 Kadıköy/ISTANBUL.
}

$\ddot{O} z$

Günümüzde nüfusun hızla artmasına paralel olarak kalabalık şehirler ortaya çıkmakta ve bu şehirlere hizmet etmek için arsa problemlerinden kaynaklı olarak dikey mimarinin bir ürünü olan yüksek binalar yaygınlaşmaktadır. Her geçen gün değişen ve gelişim gösteren farklı mimari tasarımların ürünü olan bu yüksek binalar; karmaşık ve kompleks yapılardan dolayı her hangi bir yangın anında içerisindeki canlılar açısından hayati tehlike - mal, ticari ürün, kıymetli eşyalar vs. açısından ise önemli maddi zarar ve kayıp risklerini fazlaca taşımaktadırlar.

Bu çalışmamızda İstanbul'un İlçelerinden olan Sancaktepe Belediyesi Hizmet Binası iki boyutlu AUTOCAD çizimi referans alınarak PyroSim duman tahliye simülasyonu programıla tüm bina katları çizilip binanın üç boyutlu modeli oluşturulmuştur. Oluşturulan üç boyutlu modelde yangın çıkma olasılığı yüksek olan otopark ve mutfak bölümlerinde sırasıyla araç ve yă̆ yangını olmak üzere iki farklı yangın tipi için dört farklı yangın senaryosu planlanmıştır. PyroSim programı yardımı ile bu dört senaryo için meydana gelecek duman tahliyesine ilişkin üç boyutlu hız, sıcaklık ve duman yayılımı analiz edilerek incelenmiş olup gerekli değerlendirmeler yapılmıştır.

Anahtar Kelimeler: Yüksek Bina, Duman Tahliyesi, Simülasyon, Senaryo

\begin{abstract}
Today, with the rapid increase in population, crowded cities are emerging and high buildings, which are the product of vertical architecture, are becoming widespread due to land problems to serve these cities. These high buildings are the products of different architectural designs that are changing and developing day by day; due to complex and complex structures, life-threatening goods, commercial products, valuable goods etc. In terms of significant financial loss and loss risks.

In this study, three-dimensional model of the building was constructed by PyroSim smoke evacuation simulation program with reference to two-dimensional AUTOCAD drawing of Sancaktepe Municipality Service Building which is one of the Istanbul districts. In the three-dimensional model, four different fire scenarios were planned for two different types of fire, namely car and oil fire, respectively. With the help of the PyroSim program, three-dimensional velocity, temperature and smoke emission related to smoke evacuation for these four scenarios were analyzed and the necessary evaluations were made.
\end{abstract}

Keywords: High Building, Smoke Evacuation, Simulation, Scenario

\section{GİRIŞ}

Ülkemizde her ne kadar genç nüfus oranında azalma da olsa ülke nüfusumuz her geçen gün artmaktadır. Bu artışa paralel bir şekilde kırsal kesimlerden şehir merkezlerine - kentlere doğru da bir göç hareketi olduğundan özellikle şehir merkezlerinde nüfus aşırı şekilde yoğunlaşmakta ve oldukça kalabalık şehirler ortaya çıkmaktadır. Şehirlerdeki bu hızlı nüfus artışı ve aşırı nüfus yoğunluğu kadastral ve imari açıdan planlanan şehirlerde, alanı 
büyüklüğü açısından çok da büyük olmayan imarlı arsaların ortaya çıkmasına bir nevi sebep oluyor diyebiliriz. İşte alan büyüklügü açısından çok da elverişli olmayan bu imarlı arsalarda kalabalık şehir nüfusuna hitap etmesi için üretilecek okul, hastane, belediye hizmet binası gibi kamu kurumları ve otel, özel hastane, şirket binaları vs. gibi özel sektör kuruluş binaları için dikey mimarı kullanımı bir bakıma zorunlu hale geldiğinden günümüzde yüksek bina veya yüksek yapı inşaatları giderek yaygınlaşmaktadır.

Bünyesinde bir veya birden fazla kullanım amacina hizmet verilmesi doğrultusunda inşa edilen ve yüzlerce hatta binlerce insan veya canlıyı içinde bulundurabilen bu yüksek binalar; mimari açıdan her ne kadar ihtişamlı ve estetik görünseler de özellikle bu makalede ele almış olduğumuz şekilde herhangi bir yangın olayı esnasında çok katlı ve karmaşık-kompleks yapıda olmaları, farklı kullanım sınıflarının bir arada olmasından kaynaklı yüksek yangın yüklerine sahip olmaları ve içerisinde her yaştan ve kültürden farklı insanların veya diğer canlıların olması gibi sebeplerden dolayı çok daha fazla insan veya canlı ölümü, zehirlenmesi, yaralanması ya da büyük maddi kayıp riskleri taşımaktadırlar.

Hiç şüphe yoktur ki bir yangın olayında insan veya diğer canlıların ölmelerine, zehirlenmelerine, yaralanmalarına ya da başka şekillerde ciddi zararlar görerek etkilenmelerine sebep olan ana etken yangın esnasında oluşan dumandır. $\mathrm{Bu}$ nedenden dolayı yangın olayının olduğu yerde oluşan dumanın olay yerinde bulunmaları muhtemel insan veya diğer canlıları zararlı bir şekilde etkilememesi için hızlı bir şekilde tahliye edilmesi hayati önem arz etmektedir. Günümüzde söz konusu duman tahliye sistemleri ve diğer yangın algılama ve söndürme sistemleri konusunda dünyada ve ülkemizde teknolojik gelişmeler anlamında ilerlemeler görülmektedir. Ancak yapıları ve tasarımları itibariyle çok karmaşık olan bu yüksek binalarda söz konusu duman tahliye ve yangın algılama ve söndürme sistemlerinin herhangi bir yangın olayı esnasında en etkin şekilde çalışabilmesi için bu sistemlerin, hem gerekli teknik hesaplar yapılarak teknik özelliklerinin belirlenmesi konusu hem de binaya yerleştirilmelerinde mimari olarak en etkili en optimum çözümlerin bulunması konuları oldukça önemlidir. Mimari tasarımlarda bu bahsi geçen çözümlere 1şık tutması için günümüzde oldukça kullanışlı simülasyon programları mevcuttur ki bunlardan en yaygın olanı FDS (Fire Dynamics Simulator) için geliştirilmiş olan PyroSim programıdır. [1]

$\mathrm{Bu}$ çalışmamızda İstanbul İlçelerinden olan Sancaktepe Belediyesi Hizmet Binası iki boyutlu AUTOCAD çizimi referans alınarak PyroSim duman tahliye simülasyonu programıyla tüm bina katları çizilip binanın üç boyutlu modeli oluşturulmuştur. Oluşturulan üç boyutlu modelde yangın çıkma olasılı̆̆g yüksek olan otopark ve mutfak bölümlerinde sırasıyla araç ve yağ yangını olmak üzere iki farklı yangın tipi için dört farklı yangın senaryosu tasarlanmıştır. PyroSim programı yardımı ile bu dört senaryo için meydana gelecek duman tahliyesine ilişkin üç boyutlu hız, sıcaklık ve duman yayılımı analiz edilerek incelenmiş olup gerekli değerlendirmeler yapılmıştır.

Literatür taramaları ise gelişmiş duman kontrol sistemleri dumanların yangın çıkan yerden tamamen dışarı taşınmasını veya söndürülmesini değil insanların yapıdan rahat bir şekilde tahliye edilmesini için tasarlanmaktadır. Bir bina yaygınında asıl ölüme yol açan unsurun dumandan kaynaklanan zehirlenmelerden olduğu anlaşıldıktan sonra mimarlar, mülk sahipleri ve bu tüzüklerini oluşturan resmi kurumlar duman yönetim ve kontrol sistemlerinin üzerinde çalışmalar yapmışlardır. Duman yönetim sisteminin amacı binada insan tahliyesi tamamlanana kadar geçen süreyi uzatarak çıkış için uygun bir iç ortam sağlamaktır. Yani duman yoğunluğu ile dumanın olduğu yerdeki insanların kolayca yangın bölgesinden tahliyesini sağlayacak nitelikte olmalıdır.

Böylelikle imar aşamasında olan binaların duman tahliye simülasyonları yapılarak dumanın doğru bir şekilde yönlenmesini sağlanmaktadır.

Senveli ve ark. yaptıkları çalışmada Şekil 1.1. de gösterilen İstanbul'daki önemli bir ticaret merkezinin 8 katlı kapalı otoparkında jet fanlarla dumanın kontrolü için CFD (Computational fluid dynamics) ile analizini yapmışlardır. Çalışma ile jet fanlarının konumunun ve seçiminin uygunluğunu Şekil 1.2. de gösterildiği gibi CFD analizi ile çözümleyerek uygun yöntemi ekonomik ve işlevsel yolla elde etmişlerdir. Çalışmalarını yaparken Autodesk Simulation CFD programını kullanmıştır [2].

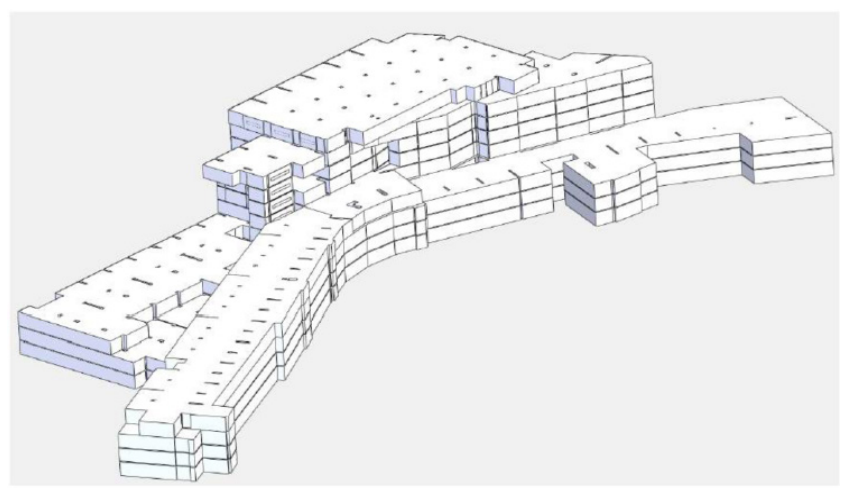

Şekil 1.1. Binanın üç boyutlu görünümü 


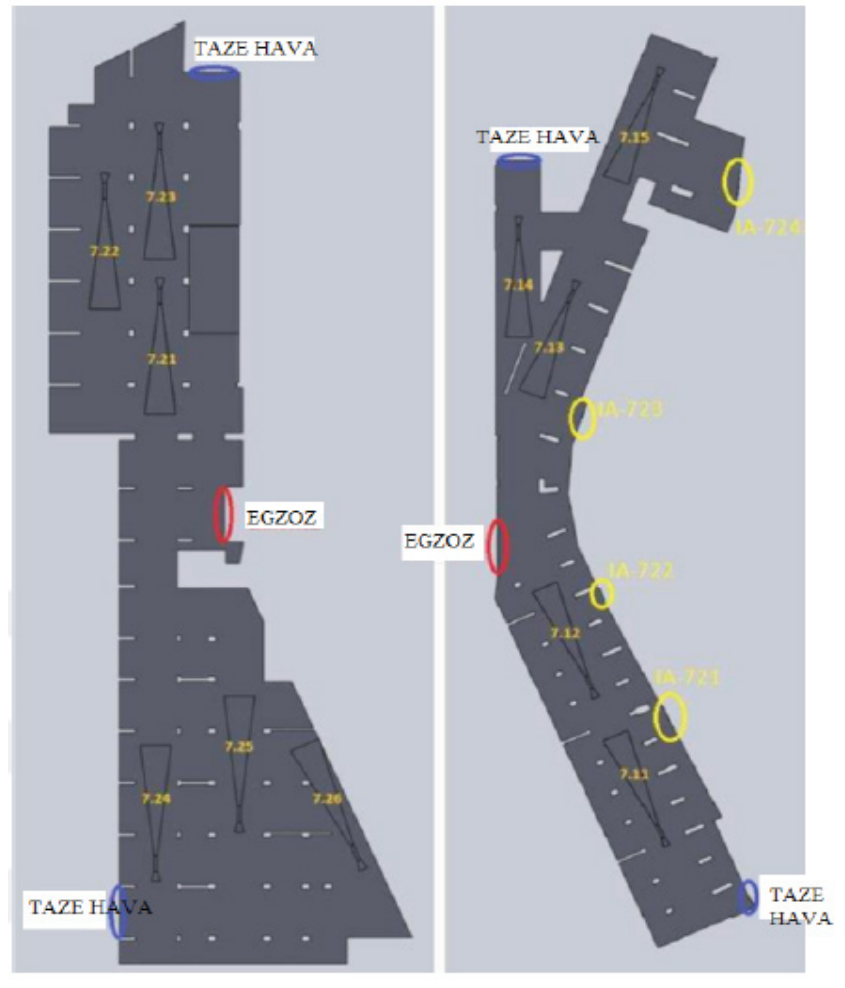

Şekil 1.2. Jet fan, taze hava ve egzoz menfezleri yerleşimlerinin gösterimi

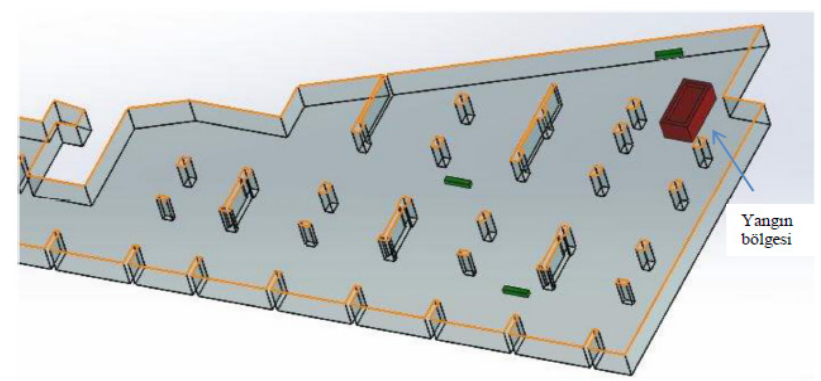

Şekil 1.3. Yangın çıkan bölge

Ticaret merkezinde duman senaryosu için 3 bölgeye ayrılmış ve yangın kaynağı Şekil 1.3. te gösterildiği gibi 14 metre uzunlukta $2 \times 5 \mathrm{~m}$ ölçüsünde gerçekleştirilmiştir. Yangın, 123 saniye sonra $4 \mathrm{MW}$ 'lık bir güce ulaşmış ve $550 \mathrm{sn}$ sonra jet fanların yerleşimlerine göre yangın bittiğindeki sıcaklık, hız ve duman yayılımı incelemişlerdir.
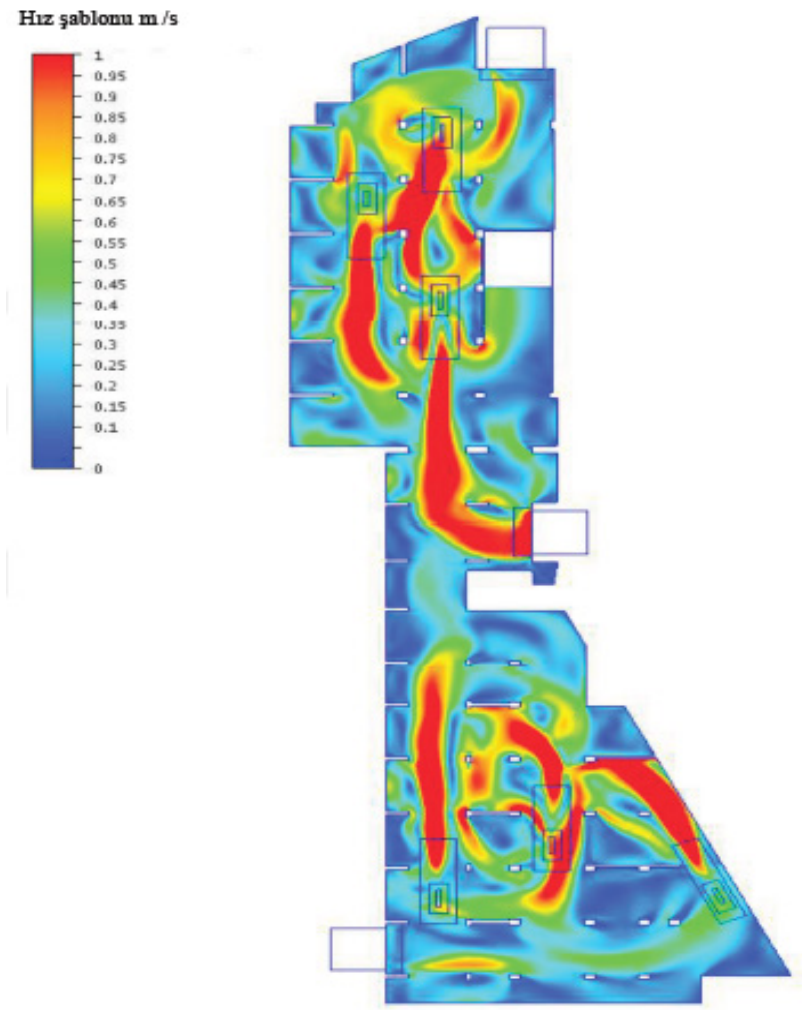

Şekil 1.4. Ticaret merkezindeki yangından hava akış hızı (1.7m)

Yaptıkları farklı analizler sonucunda gerçekleştirdikleri jet fan konumlandırmalarının uygun olduğunu Şekil 1.4 'de görüldüğü gibi ortaya koyulmuştur. Duman akış hızının $0,1 \mathrm{~m} / \mathrm{s}$ 'nin altına düşmemesi akışın durmadığının bir kanıtıdır. Böylelikle senaryosu gerçekleştirilen kat içinde ölü hacim kalmadığını analizler sonucu görmüşlerdir.

Şekil 1.5. te London's King's Cross metro istasyonu için yapılmış hesaplamalı akışkanlar dinamiği (CFD) simülasyon sonuçlarından elde edilen veriler eşliğinde tipik bir metro istasyonu olan ve modern metro istasyonu tasarımında mekanik kontrol sistemleri standart olan GongGuan metro istasyonunun duman kontrol şemasının etkinliğini araştırılmıştır. Üç boyutlu duman akış alanları, çeşitli yangın türleri altında hesaplamalı akışkanlar dinamiği teknikleri kullanılarak hesaplanmış ve sonuçlar çeşitli düzlemlerde gösterilmiştir [3]. 


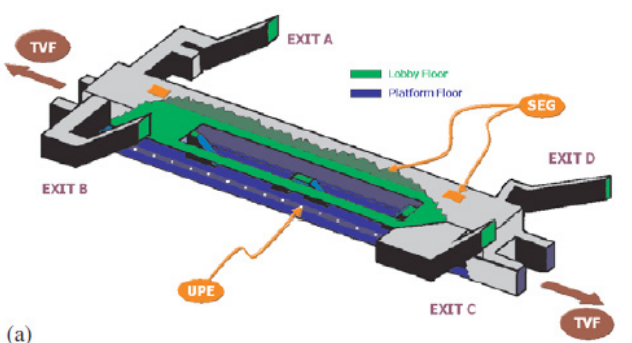

(a)

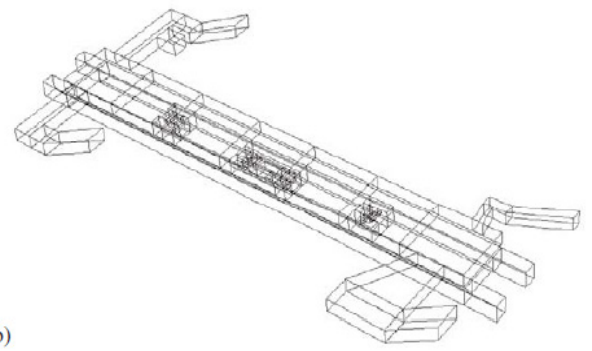

(b)

Şekil 1.5. Gung-Guan metro istasyonunun şematik çizimi
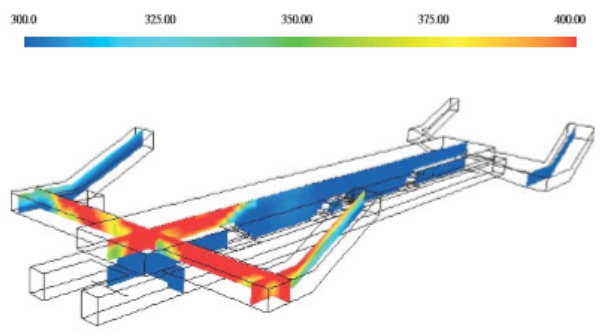

(a)
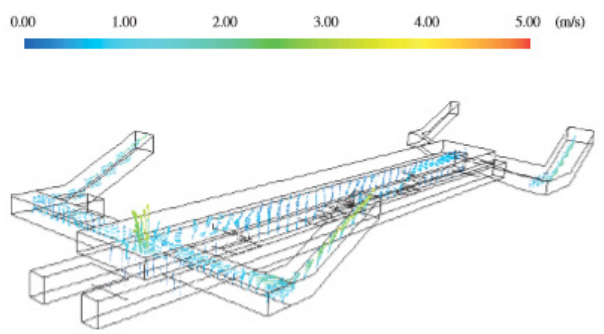

(b)

Şekil 1.6. Gung-Guan metro istasyonunun a)sıcaklık b) hız gösterimi

Yapılan farklı analizler sonucunda fanların yerleşimi ve yangına etkileri doğru konumlandırmada ne kadar önemli olduğunu görmüşlerdir. Şekil 1.6 da görüldüğü üzere lobi kattnın iki uçundaki çıkacak bir yangında merdiven boşluklarından hızlı bir şekilde duman tahliyesi yapıldığını ikinci bir senaryo ise istasyon merkezinde çıkacak bir yangında duman tavana doğru ilerledikten sonra kenarlara yayılmaya başladığında fanların dumanı emmesi sayesinde insanların tahliye kolaylaştığını görmüşlerdir. Modern metro istasyonlarında duman kontrol sistemleri standart olduğundan yapılan analizlerin olumlu sonuçlar vermesi çıabilecek yangınların büyük ölçüde benzer konfigürasyonda olacağı düşünülerek metro istasyonu için standartların yeterli olduğunu görmüşlerdir.

\section{TANIMLAR}

- Kamu Binası: Bir çevrede ya da bölgede yaşayan halka, topluluğa, insanlığa hizmet maksadıyla inşa edilmiş olan okul, hastane, belediye hizmet binaları, havaalanı terminal binaları, camiler vb. gibi binalardır.

- Yüksek Bina: Ülkemizde yürürlükte olan Binaların Yangından Korunması Hakkında Yönetmelik'te yüksek bina; yüksekliğin ilgili binaya ilişkin zemin kotundan çatı seviyesine kadar olan bina yüksekliğinin 21,50 m'den daha fazla olduğu veya yüksekliğin ilgili binanın en alt bodrum katından alınıp çatıdaki saçak seviyesine kadar aradaki mesafe olarak tanımlanan yap1 yüksekliğinin $30,50 \mathrm{~m}$ 'den fazla olan binalar olarak tanımlanmaktadır [4].

- Duman Tahliyesi: Yangın olayı esnasında oluşan ve insan ve diğer canlıların sağlığı açısından olumsuz sonuçların ortaya çıkmasına sebep olabilecek olan dumanın ilgili mahalden veya ortamlardan uzaklaştırılmasıdır.

- Simülasyon:Gerçekyadaherhangibiraraştırmakonusu üzerine tasarlanan bir sistemin, bilgisayar ortamında çeşitli programlar vasıtasıyla modellendikten sonra oluşturulan modelle sistemin çalıştırılması gayesine yönelik olarak, sistemin davranışını tespit edebilmek veya değişik olasılıkları değerlendirebilmek için deneyler yürütülmesi, bu sistemlerin özelliklerini ve davranışlarını bilgisayar aracılığıyla değerlendiren bir tekniktir.

\section{DUMANIN ZARARLI ETKÍLERI}

Dumanı; yangın olayı esnasında açığa çıkan katı, sıvı ve gaz tanecikleri ile dışarıdan taze havanın katılımıyla oluşan karışım olarak tanımlayabiliriz. Duman, içeriğinde bulunan zehirli gazlar ve maddelerden kaynaklı insan ve diğer canl1ların hayatını ciddi şekilde doğrudan etkilemekte ve büyük zararlar verebilmektedir. Dumanın içinde ihtiva ettiği bazı gazlardan kaynaklı zehirleyici ve boğucu etki yarattığı ve bu durumun da solunum sistemlerine ciddi şekilde zarar vererek hayati tehlikelere yol açtığı bilinen bir gerçektir. Duman ayrıca içinde ihtiva ettiği bu zararlı gaz ve taneciklerden dolayı gözlerde ve deri tabakasında da aşırı tahriş edici etkiler ortaya çıkarabilmekte ve yanıklara sebebiyet verebilmektedir. Aşağıdaki tabloda dumanın içinde ihtiva ettiği bazı zehirli gazların tehlike sınırları belirtilmiştir [5]. 
Tablo 3.1. Bazı zehirli gazların tehlike sınırları [6,7]

\begin{tabular}{|l|l|}
\hline Zehirli Gazlar & Tehlike Sınırı (ppm) \\
\hline Karbonmonoksit & $50-100$ \\
\hline Formaldehit & 2 \\
\hline Formikasit & 5 \\
\hline Metil Alkol & 200 \\
\hline Asetik asit & 10 \\
\hline Hidrojen Klorür & 5 \\
\hline Hidrojen Siyanür & 10 \\
\hline Azot oksit (ler) & 5 \\
\hline Kükürt Dioksit & 5 \\
\hline Kükürtlü Oksijen & 10 \\
\hline Amonyak & 25 \\
\hline
\end{tabular}

\section{DUMAN KONTROL VE YANGIN SÖNDÜRME SISTEMLERI}

Yangının erken algılanması ve bu algılama neticesinde yangına erken tepki verebilmek yangının söndürülmesi ve sonuçlarının her açıdan daha az zarar veya kayıp açısından oldukça önemlidir. Buna paralel olarak yangın olayında insan ve diğer canlıların hayatına birinci derecede olumsuz etki eden dumanın hızlı bir şekilde tahliyesi de hayati önem taşımaktadır. Aşağıda yangına erken tepki verilmesi, hızlı bir şekilde sogutulması amaciyla kullanılan otomatik yağmurlama sistemi (sprinkler sistemi) ve özellikle otopark, tünel vs. gibi kapalı alanlarda kullanımı oldukça yaygın olan mekanik duman tahliye (jet fan) sistemleri hakkında bilgiler verilmiştir.

\subsection{Otomatik Yağmurlama Sistemi (Sprinkler Sistemi)}

Otomatik yağmurlama (sprinkler) sistemi, Şekil 4.1. de görseli sunulduğu şekilde yangına erken müdahale edebilmesi, yangını bastırma, bölgesel soğutmayı ve söndürme ekipleri olay yerine ulaşıncaya kadar yangını sınırlamak amacı ile kurulan ve su püskürtmesi yapan otomatik sistemdir. Yağmurlama sistemi yağmurlama başlıkları, bağlantı ekipmanları, borular ve askılar, tesisat kontrol vanaları, akış göstergeleri, uyarı zilleri, su pompaları ve acil durum güç kaynağı gibi elemanlardan oluşmaktadır. Yağmurlama sistemlerinde uyulmas1 gereken standart TS EN 12259 olmalıdır [8].

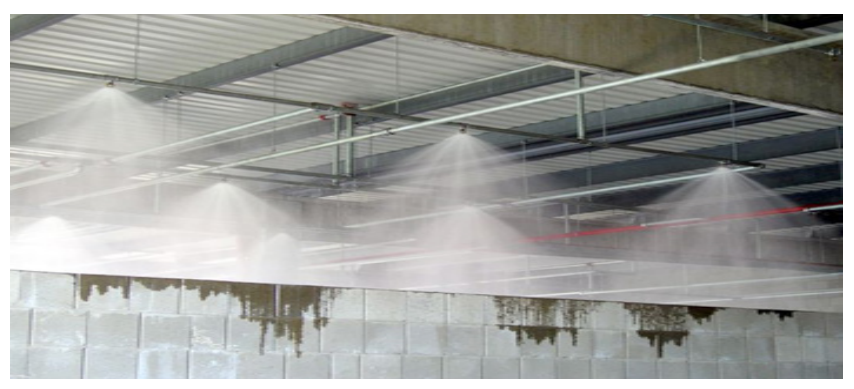

Şekil 4.1. Otomatik yağmurlama sistemi

\subsection{Mekanik Duman Tahliye (Jet fan) Sistemleri}

Mekanik duman tahliye sistemleri; Şekil 4.2. de örneği sunulduğu şekilde yangın esnasında oluşan dumanın hızlı bir şekilde tahliyesini sağlayan mekanik sistemlerdir. Pratikte en bilinen uygulaması jet fanlardır. Jet fanlar yarattıkları itme kuvveti ile ortamdaki hava kütlesine hızlı bir şekilde vurarak geniş bir alandaki havayı iterek ve sürükleyerek harekete geçirmektedirler [9].

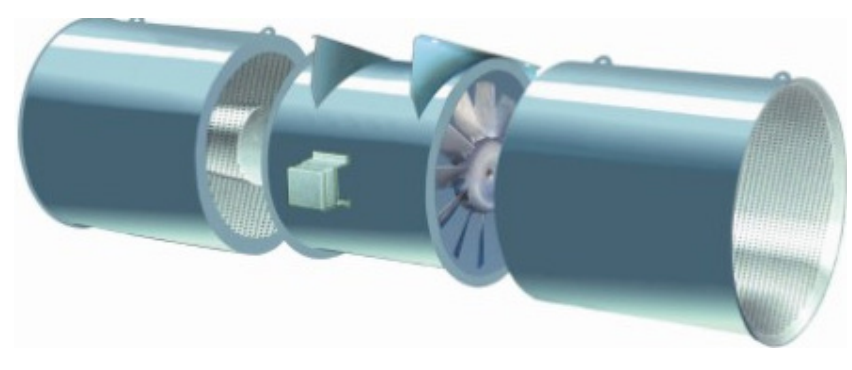

Şekil 4.2. Jet fan sistemi

\section{MALZEME VE YÖNTEM}

\subsection{Boyutlu CAD Modeli İçin Kullanılan Yazılımlar}

Üç boyutlu CAD modeli oluşturmak için AutoCad ve PyroSim programlarından faydalanılmıştır. AutoCad programıyla hazırlanmış Sancaktepe Belediye Binası tüm katların ayrıntılı ölçüleri 2 boyutlu olarak bulunmaktadır. PyroSim programı yardımı ile tüm bina katları çizilip 3 boyutlu bina modeli oluşturulmuştur. Bina 2 farklı bölgede ikişer durum için analize hazırlanmıştır.

Mutfakta çıkabilecek bir yağ yangının sprinkler aktif olduğunda ve sprinkler aktif olmadığındaki duman dağılımı incelenmiştir.

Bodrumda çıkabilecek bir araç yangınında jet fanlar aktif olduğundaki durum ve jet fanlar aktif olmadığı durumdaki duman dağılımı incelenmiştir.

\subsection{PyroSim Yazılımı}

Kullanılan PyroSim programı Fire Dynamics Simulator (FDS) için geliştirilmiş bir grafik ara yüz programıdır. Karmaşık yangın modellerinin tüm detaylarının hızlı bir şekilde oluşturulabilmesi ve yönetilebilmesini sağlar.

PyroSim de çoklu ağ yapısı ve bu yapının doğruluğunu teyit etmek için araçlar bulunur. PyroSim, FDS' te kullanılabilen birçok özelliğin kişiselleştirilebilir ve oluşturulan modele hazır olarak aktarılabilir reaksiyon, sıcaklık dedektörleri, malzeme, parçacık, yüzey parametreleri gibi model 
parametreleri için geliştirilmiş kütüphaneleri bulunmaktadır. Bu özelliklerinden dolayı model oluşturma süreci daha hızlı ve daha az hata ile yürütülmektedir. Bu ara yüz model oluştururken aşamaların hepsi 3 boyutlu olarak görüntülenebileceği için hatalar minimize edilmiş olur. PyroSim ara yüzü FDS programının mevcut tüm özelliklerini kısıtlama olmaksızın kullanımına imkân verdiğinden dolayı kullanıcrya daha kolay, daha hızlı ve minimum hata ile modelleme yapma imkânı ve 3 boyutlu simülasyon imkanı sunmaktadır.

\subsection{A $\breve{g}$ Yapısı (Mesh)}

PyroSim programı ağ yapısını arka planda HAD çözücüsü olarak çalıştırmaktadır. HAD yazılımında akış çözümü Large Eddy Simılation (LES) türbülans modeli yapıldığ için katı modeli akış hacminden ayırarak dörtgensel ağ yapısı oluşturmaktadır. Böylelikle modeldeki kıvrımlı yüzeyler ağ yapısının büyüklüğüne göre dörtgensel olarak bölünmektedir.

PyroSim'de yangının simülasyon hassasiyetinin iyi olması için boyutsuz bir ifade olan $D$ karakteristik yangın çapı tanımlanır. Alevin özelliği, aşağıdaki boyutsuz sayı olan $D$ formülüne direkt bağlantılıdır.

$D=\left(\frac{Q}{\infty_{\infty} p_{\infty} g^{\frac{1}{2}}}\right)_{(5.1)}^{\frac{2}{3}}$

$D^{*}:$ Karakteristik Yangın Çapı (m)

$Q$ : Yangin Yükü $(k W)$

$\infty$ : Gaz Yoğunluğu $\left(\mathrm{kg} / \mathrm{m}^{3)}\right.$

$c_{p}:$ Kirli Gazların Özgül Islsı $\left(\mathrm{J} / \mathrm{kg}^{\circ} \mathrm{C}\right)$

$T_{\infty}$ : Duman Ortam Sicakliğ (Kelvin)

Farklı senarvolarda hassas ve yüksek doğrulukla çözülebilmesi için $\frac{D}{d x}$ oranının 4 ile 16 arasında olması tavsiye edilmektedir [10].

Pyrosim; Fire Dynamics Simulator (FDS) için geliştirilmiş karmaşık yangın modellerinin tüm detaylarının oluşturulabilmesini ve tanımlanan model doğrultusunda yangının analiz edilmesini sağlayan bir grafik ara yüz programıdır. PyroSim programı dahilinde yangın olayı için herhangi bir mekan 3 boyutlu olarak oluşturulabileceği gibi AutoCAD DXF ve DWG veya mevcut olan FDS uzantılı dosyaların programa aktarılması ile de model oluşturulması mümkündür. Tüm bunların yanında GIF, JPG veya PNG uzantılı dosyaların PyroSim'e aktarılıp oluşturulan modelde arka plan görseli olarak kullanmak da mümkündür [11].

\subsection{Analizler}

Yangın modellememiz, yüksek bina sınıfına giren içerisinde atriumlu alana sahip olan Sancaktepe Belediye Binası'nda, 2 farklı bölgede 4 farklı senaryo şeklinde tasarlanarak çözümleme yapılmıştır.

Binanın teknik ölçüleri AutoCad programında çizilmiş mimarı projeden alınmıştır. Bu ölçüler kullanılarak Şekil 5.1. de gösterildiği gibi PyroSim programında üç boyutlu hale getirilmiştir. Üç boyutlu halde olan binanın yangın çıkma olasılığı yüksek olan mutfak ve otopark bölgesine yangının çıkabileceği yer çizilmiştir. Binanın yangının, jet fanların ve sprinklerin özellikleri bu kısımda oluşturulmuş olup aşağıda görselleri sunulmaktadır.

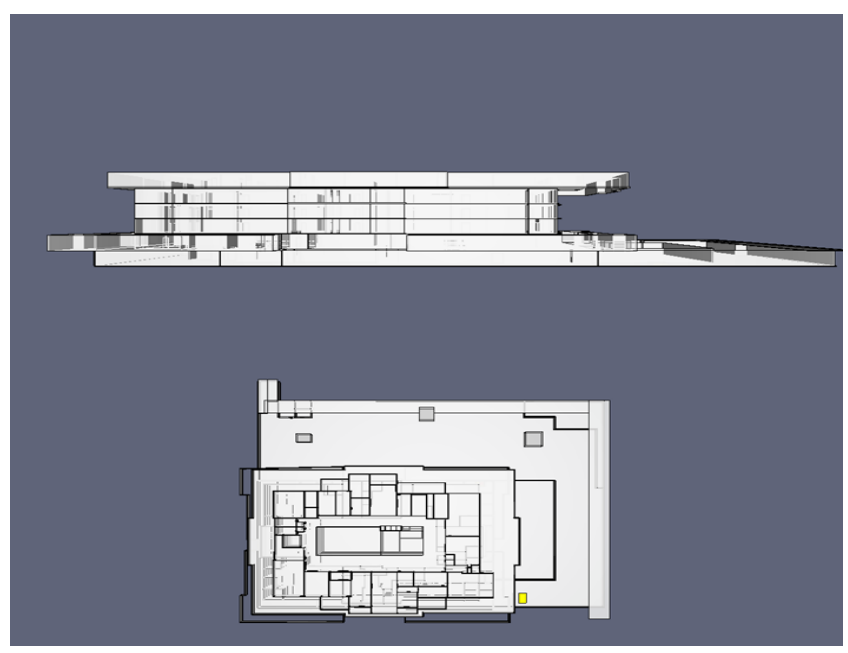

Şekil 5.1. Belediye binası görünüşü

Üç boyutlu halde modellenen binada sprinkler başlığımız Şekil 5.2. de gösterildiği gibi tanımlanmıştır.

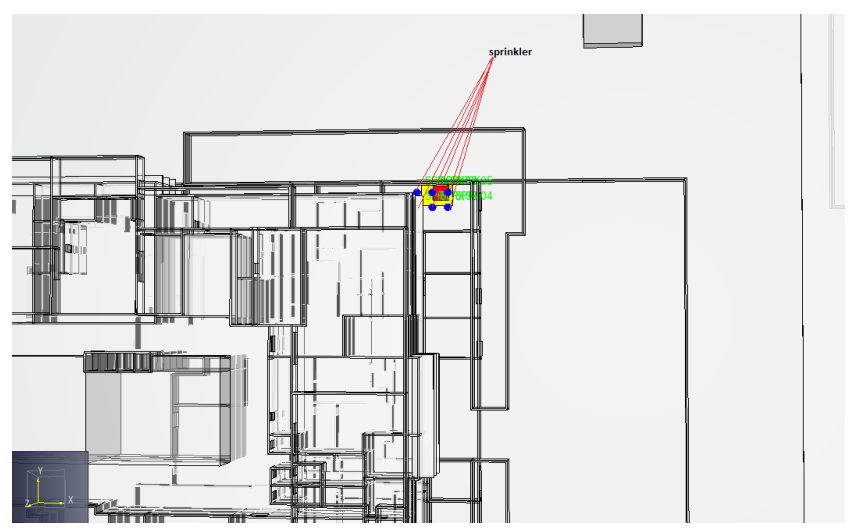

Şekil 5.2. Bina içerisindeki sprinkler gösterimi 
Jetfanlar ise Şekil 5.3. de gösterildiği şekilde otopark bölgesinde konumlandırılmışlardır.

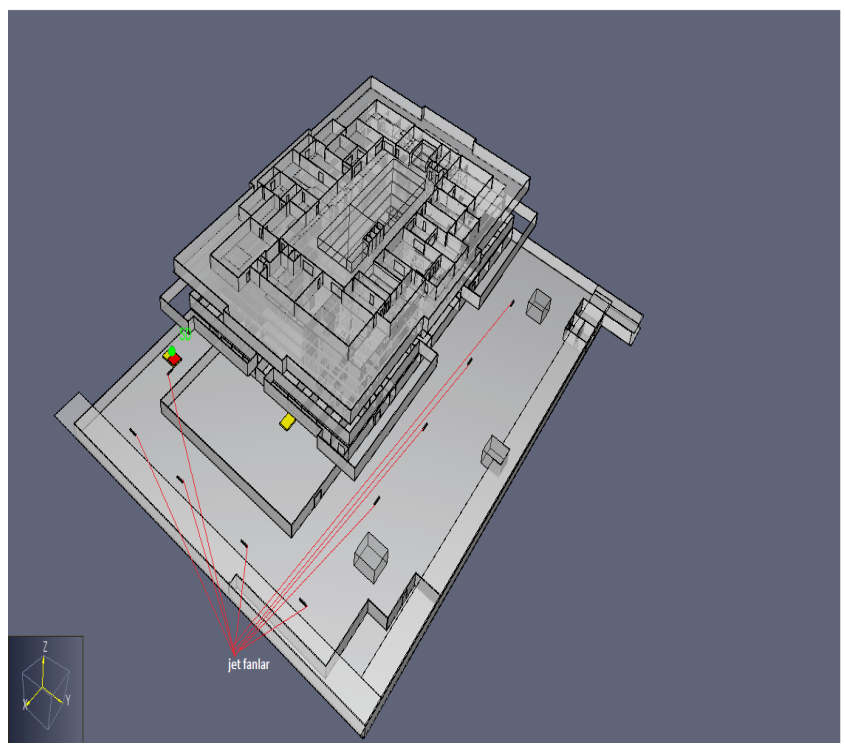

Şekil 5.3. Bina içerisindeki jet fan gösterimi

Analiz çalışmalarına başlamadan yapılan varsayımlar;

- Çizilen projede duman sızıntısı olmayacak şekilde bina tasarımı üç boyutlu şekilde modellenmiştir.

- Ortam sicaklığı $20^{\circ} \mathrm{C}$ olduğu kabul edilmiştir.

- Dış ortam basıncı ve rüzgar ihmal edilmiştir.

- Duman tahliyesi yapan 9 jet fanın aynı anda sorunsuz çalıştığ varsayılmıştır.

- Mutfakta bulunan sprinkler sisteminin ilgili sensörler ile bölgesel çalıştı̆̆ kabul edilmiştir.

Analiz, 300 saniye için 2 Farklı bölge için 4 farklı senaryo tekrardan düzenlenmiştir. Bu senaryolar şunlardır:

- Binanın mutfak katında çıkacak bir yağ yangınında sprinkler sistemi aktif değilken

- Binanın mutfak katında çıkacak bir yağ yangınında sprinkler sistemi aktifken

- Binanın otopark katında çıkacak bir araç yangınında hiçbir sistem aktif değilken

- Binanın otopark katında çıkacak bir araç yangınında jet fanlar aktifken

PyroSim programı yardımı ile bu dört senaryo için meydana gelecek duman tahliyesine ilişkin üç boyutlu hız, sıcaklık ve duman yayılımı analiz edilerek incelenmiş, incelemelere ilişkin bazı analiz durumları aşağıdaki şekillerle sunulmuş, devamında da gerekli değerlendirmeler yapılmıştır.

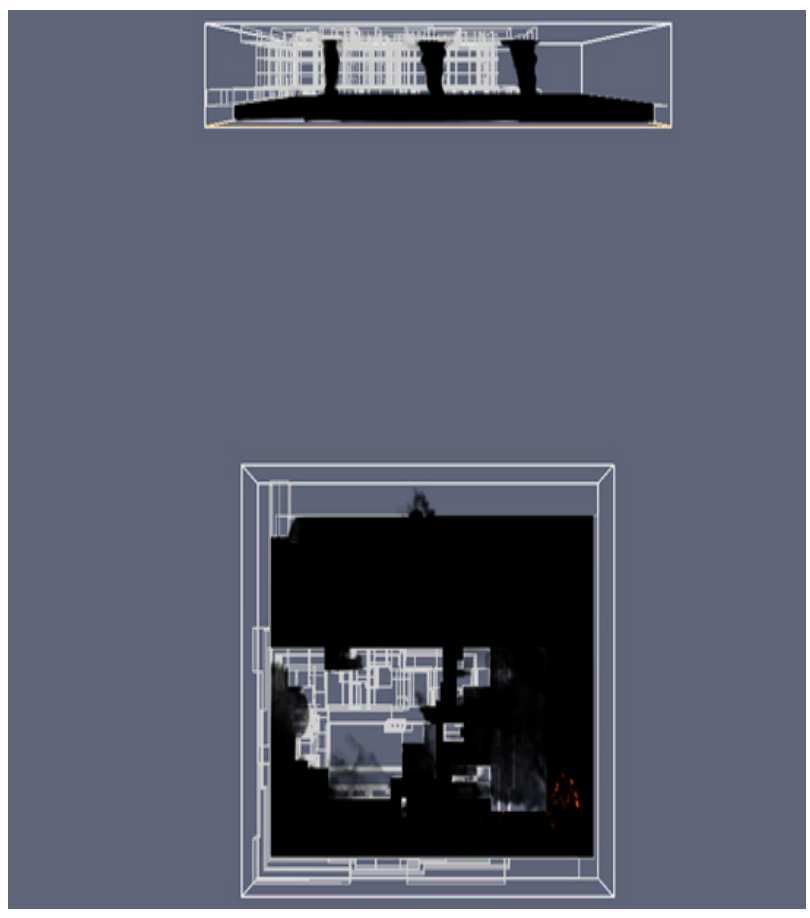

Şekil 5.4. 0-300 saniyede bina içerisindeki duman da$\breve{\text { ğ}} 1 \mathrm{lim} 1$
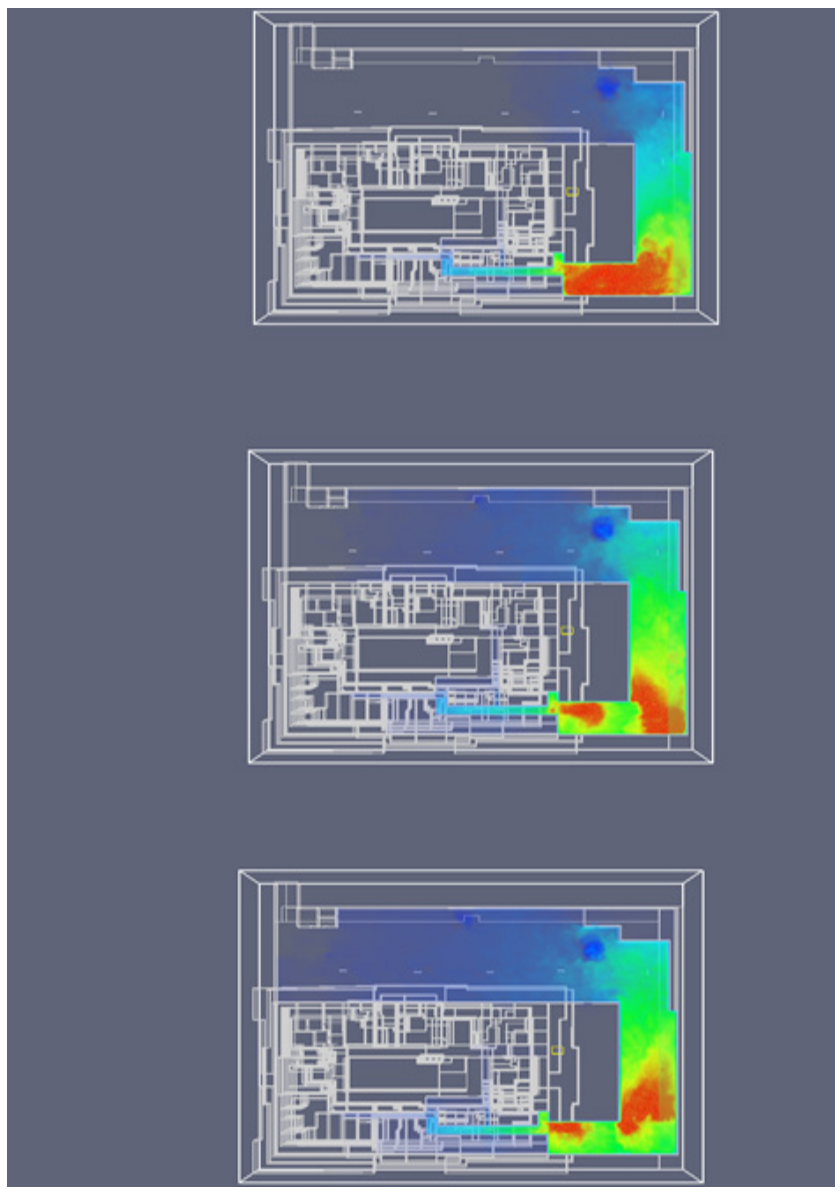

Şekil 5.5. 0-300 saniyede bina içerisindeki 3D sıcaklık görünümü 


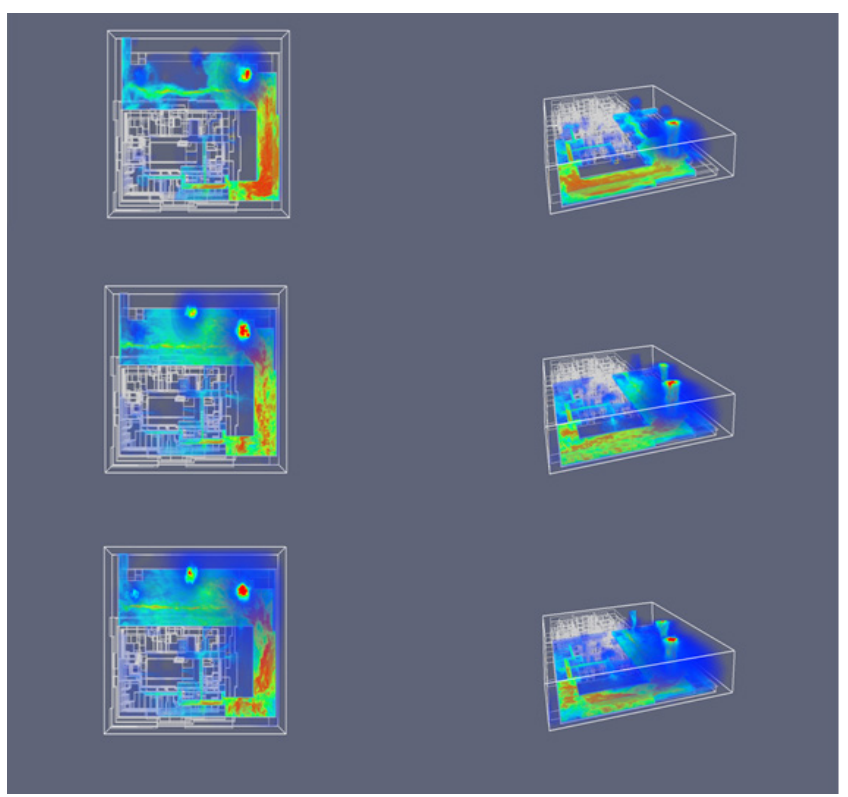

Şekil 5.6. 0-300 saniyede bina içerisinde 3D hız görünümü

Belediye binasında duman analizleri incelendiğinde ilk senaryo olan mutfakta yağ yangını durumunda sprinklerin aktif olmadığı zaman dumanın 40 saniye sonra yemek yenilen bölgeye ulaştı̆̆ görülmüştür. Dumanın 120. saniyede ise otopark kısmına geçtiği ve 166. saniyede yemek masalarının olduğu personel yemek yeme alanının tamamen dumanla dolmakta olduğu görülmüştür.

Belediye binasında duman analizleri incelendiğinde ikinci senaryo olan mutfakta yağ yangını durumunda sprinklerin aktif olduğu zaman dumanın 52. saniyede yemek yeme alanına ulaştı̆̆ görülmektedir. Duman 140 saniye sonunda otoparka çıkmaya başlamış ve 181. saniye sonunda personel yemek yeme alanının tamamen dumanla kaplandığı görülmektedir. 253. saniyede otopark yaya girişi için açılmış olan 3 girişinden biri olan sağdaki girişinden çevreye duman çıkışı ve bina içindeki atriumlu alana dumanın dolmaya başladığı görülmektedir.

Belediye binasında duman analizleri incelendiğinde üçüncü senaryo olan otoparkta araç yangını durumunda jet fanlar aktif olmadığ zaman duman yangının 50. saniyesinde zemin kata, otopark yaya girişi için açılmış olan 3 girişten sağ taraftaki girişten de çevreye (dişarıya) ulaştı̆̆ 1 görülmektedir. Dumanın 140 saniye sonunda binadaki atriumlu alana dolduğu görülmektedir.

Belediye binasında duman analizleri incelendiğinde dördüncü senaryo olan otoparkta araç yangını durumu jet fanlar aktif olduğu zaman dumanın yangının 56. saniyesinde otopark yaya girişi için açılmış olan 3 girişinden biri olan sağdaki girişten çevreye (dışarıya) çıktığ 1 görülmektedir. 300 saniye sonunda dumanın bina içindeki atriumlu alana sirayet etmediği, otopark çıkışlarından tahliye edildiği görülmektedir.

\section{SONUÇ VE DEĞERLENDİRMELER}

Farklı senaryolar için düzenlenmiş yangın analizlerinde dumanın nasıl yayıldığı, hangi yolları kullandığı görülmüştür. Yangın durumlarında sprinklerin çalışarak dumanı baskılaması ve yangını yavaşlatması sayesinde insan tahliyesi için $\% 15^{\prime}$ lik zaman kazanımı olduğu görülmektedir. Jet fanlı yangın durumlarında 9 fanın eş zamanlı çalışmasıyla bina içerisindeki atriumlu alana duman dolmadığı ve insan tahliyesi için \% 25.4'lük zaman kazanımı olduğu görülmektedir.

Mutfakta yağ kaynaklı çıkacak yangın için mutfağın yemekhane ve otoparkla bağlantısını sağlayan kapılar yangına karşı korunaklı hale getirilip olası insan yoğunluğundan dolayı özellikle yemekhane ve yüksek yangın yükünden dolayı otoparka yangının sirayet etmesinin geciktirilerek yangın güvenliği açısından iyileştirmeler sağlanmalıdır.

Gerek bodrum kattaki otopark bölümünde araçlardan kaynaklı gerekse yine bodrum kattaki mutfak bölümünde (yağ yangını) çıkacak yangınların binanın zemin katına (atriumlu alan) ulaşmaması için binanın bodrum kattan zemine geçişleri sağlayan merdivenlerinin olduğu bölümde binanın merkezi yangın sistemiyle irtibatlı sadece yangın halinde aldığı elektronik sinyaller doğrultusunda kapanan elektromanyetik yangın kapıları takılmalıdır.

Otopark araç yangınında jet fanlar aktif olmadığı zaman atriumlu bölüme dolan dumanın hızlı ve güvenli şekilde tahliyesini sağlamak için atriumlu alanın üst kısmındaki cam çatı bölümünde binanın merkezi yangın kontrol sistemine elektronik sinyallerle bağlı uygun ebatlarda duman tahliye kapakları yerleştirilmelidir.

Otoparkta jet fanlı veya jet fan olmadığı durumlarda meydana gelebilecek herhangi bir yangın esnasında yang1nın (dumanın) binanın iç kısımlarına sirayet etmemesi veya sürenin geciktirilmesi adına otoparktan binaya geçiş noktalarındaki kapılar yangına karşı korunaklı hale getirilmelidir ayrıca bu bölümlerde bina içini koruma adına basınçlandirma uygulamaları da yapılmalıdır.

Yangın; başlı başına insan ve diğer canlıları maddi ve manevi açıdan büyük zararlara uğratabilen olumsuz bir olayken her yaştan, her kesimden ve her kültürden insanların ve insanlarla birlikte diğer canlıların da içinde bulunabileceği yüksek kamu binalarında meydana gelecek karmaşa ve kaostan ötürü çok daha felaketlere ve vahim sonuçlara yol açma riskini fazlaca taşımaktadır. PyroSim programı veya literatürde bilinen diğer simülasyon programlarının 
kullanılması vasıtasıyla bu tarz yüksek binalar; daha tasarım aşamasındayken yangın senaryoları dahilinde analiz edilmeleri imkanıyla gerektiğinde mimari detaylar revize edilerek binanın yangın güvenliği konusunda iyileştirmeler yapılabilmekte, binaya uygulanacak olan tüm yangın güvenlik sistemlerinin hem konumlandırılmaları hem de en etkin şekilde çalışmalarına yönelik teknik özellikleri noktasında optimum çözümler elde edilebilmektedir.

\section{TEŞEKKÜR}

$\mathrm{Bu}$ çalışmada desteğini ve kıymetli olurlarını bizden esirgemeyen çok değerli Sancaktepe Belediye Başkanımız Sn. Av. Şeyma DÖĞÜCÜ Hanımefendiye teşekkür ve şükranlarımızı arz ederiz.

\section{KAYNAKLAR}

[1] ARPACIOĞLU, Ü., Eriç, M., Ekim 2005, Yangın Olgusu ve Yüksek Yapılarda Yangın Güvenliği, Yangın Güvenlik Dergisi, (90): 62-75.

[2] Nükleer Güç Santralı Uygulamalarında Seçilen Yangın Modellerinin Doğrulanması ve Onaylanması NUREG 1824, ABD Nükleer Düzenleme Komisyonu, 2007.

[3] Chow, T.T., Zhang, L., and Tsang, C.F., Building Energy \& Environmental Technology Research Unit, International Journal on Architectural Science, Volume 7, 2006.
[4] KILIÇ, M. (2003). Yapılarda Yangın Güvenliği ve Söndürme Sistemleri, Uludağ Üniversitesi Mühendislik-Mimarlık Fakültesi Dergisi, Cilt 8, (1), s. 59 - 70.

[5] Çebi, F. (2013) Atrium İçeren Çok Katlı Binalarda Duman Dağılımının Sayısal İncelenmesi. Yüksek Lisans Tezi, İstanbul Teknik Üniversitesi Fen Bilimleri Enstitüsü, Türkiye, s. 17.

[6] Küçük, S.,"Yanma Sirasında Oluşan Yanma Ürünleri ve İnsan Sağlığı Üzerindeki Olumsuz Etkileri”, Yüksek Lisans Tezi, Marmara Üniversitesi Sağlık Bilimleri Enstitüsü, İstanbul, 7-69 (2001).

[7] NFPA-720 "Carbonmonoxide Risks at Home", National Fire Protection Association, Denver, USA (1988).

[8] BYKHY, 2009, Binaların Yangından Korunması Hakkında Yönetmelik.

[9] Cvsair, Car Park Ventilation System, Jet Fan Sistemi, https:// cvsair.com.tr/wp content/uploads/2018/05/JETFANLI-OTOPARK-HAVALANDIRMA-SI\%CC\%87STEMI\%CC\%87.pdf, (Ocak.2019).

[10] İnternet: https://www.thunderheadeng.com/?s=mesh (Ocak.2019).

[11] Altay, M. (2016) Tünel Yangınlarının Modellenmesi Ve Etkin Parametrelerin Modellemedeki Gerçekçiliğinin İncelenmesi. Yüksek Lisans Tezi, Bursa Teknik Üniversitesi Fen Bilimleri Enstitüsü, Türkiye, s. 22-23. 